\title{
Meditsiin on-line
}

\begin{abstract}
Mare Kõiva
Teesid: Artiklis iseloomustatakse on-line meditsiini kujunemist ning erinevaid arsti-patsiendi arvutivahendatud suhtlemise võimalusi. Meedikutele mõeldud ja meedikute loodud keskkondades on arsti-patsiendi suhtlemisakti üleehitus ja sõnakasutus formaalne, suhtlemine distantseeritud. Patsientide diskussioonirühmade kirjalikku interaktsiooni iseloomustavad individuaalse stiili ja keelekasutusega vabad arutlused, mille vorm ulatub informeerivast teatest narratiivideni. Lähemalt iseloomustatakse ühe arstimisjuhtumi ümber arenenud mõttevahetust ja selle ühisjooni suulise silmast silma dialoogiga.

Meditsiini või konkreetse haigusega seotud kooslused ei moodusta püsivat sotsiaalset võrgustikku. Selliseid rühmasid seob informatsioon ja narratiivid ning nad on olulised emotsionaalse tasakaalu saavutamisel. Dialoogi alustatakse eksperthinnangu hankimiseks või andmiseks, sageli asendab on-linesuhtlemine off-line-kogukonnas puuduvaid võimalusi.
\end{abstract}

Märksõnad: arvutivahendatud kommunikatsioon, arsti-patsiendi suhtlemine, kommunikatsioon, on-line-meditsiin, patsiendinarratiiv

Kui me uurime meditsiini sotsiaalkultuurilise nähtusena ning eemaldume bioloogiale keskendunud ja haigusele orienteeritud perspektiivist, siis märkame, et kõigis ühiskondades - nii traditsioonilistes kui ka moodsates - kujutab meditsiin endast ideede ja praktika koherentset süsteemi, mis ümbritseb haiguse probleemi ja tegeleb eeskätt meditsiinilise hoolitsusega (Kleinman 1980). Tsitaat pärineb 20. sajandi nimeka meditsiiniantropoloogi Arthur Kleinmani sulest. Tema uurimistöö tulemusena seadustati rida etnopsühhiaatrilisi termineid ja haiguskirjeldusi ning lülitati need psühhiaatriliste haiguste ametlikku loetellu.

Meditsiinisüsteem on mõistetav vastava kultuuri kontekstis, antud juhul on artikli siht iseloomustada on-line-meditsiini arengut Eestis, mida on tunnustatud ühe kiireima infotehnoloogiliste lahenduste kasutuselevõtjana. Käesolevas uurimuses on vaatluse all kaks suurimat eestikeelset meditsiininõuannete portaali arst.ee ja kliinik.ee, terviseportaal inimene.ee ning foorumid 
Eesti Ämmaemandate Ühingu ja Eesti Diabeediliidu kodulehekülgedel. Internet kui sotsiaalseid ja kultuurilisi muutusi kiirendav faktor on viimasel aastakümnendil olnud oluline kultuuriliste praktikate konstrueerimise mõjutaja. Vaatamata ruumilistele vahemaadele tagab Internet infomatsiooni ja kapitali voogude kiire liikumise. Näiteks on teada, et 2002. aastal pöördus 14\%, 2003. aastal $13 \%$ ja 2004. aastal $28 \%$ terviseuuringutes osalenud intervjueeritutest arsti poole veebi kaudu. Sealjuures 15-24-aastaste vanuserühmas hankis $44 \%$ ja vanemates vanuserühmades $28 \%$ küsitletutest oma perearsti kohta informatsiooni Interneti vahendusel (Kalvet 2006).

Kategoriseerides Interneti suhtlusrühmi suuremateks üksusteks, nagu: 1) tsiviil/poliitilised, 2) religioossed/heategevad, 3) sotsiaalsed 4) haridus/professionaalsed, näeme, et neil kõigil on formaalse kommunikatsiooni kõrval oma spetsiifiline informaalne kommunikatsioon ning oma (rühma)pärimus.

\section{Muutunud küberkeskkond}

Traditsioonilise silmast silma suhtluse kõrval on meditsiinialaste konsultatsioonide juures aktuaalne suhtlemine telefoni ja tavaposti teel. Lai on ka elektrooniliste võimaluste valik, kus meditsiiniinfo liigub või mida kasutatakse igapäevases organisatsioonilises suhtlemises: arvutipõhine otsesuhtlus, isikult isikule saadetud e-meilid, e-meili suhtlusrühmad ja listserverid, uudiserühmad (newsgroup), jututoad (chat room), foorumid, on-line-ajakirjanduse diskussiooniruumid (online bulletin board or discussion board). Passiivse eneseväljendusvahendi ja tekstikogumikuna toimivad isiklikud, temaatilised ja institutsionaalsed veebilehed, blogid jm veebisuhtlemise võimalused, mis pole pelgalt suhtluskeskkonnas arendatud kommunikatsiooni liigid, vaid paljudel juhtudel võimalus kuuluda kindlasse virtuaalsesse kogukonda. See muudab tänase Interneti identiteedi ja mentaalsuse loomise keskkonnaks, mis võimaldab väljendada loovust, võimu, institutsionaalsust ja individuaalsust.

1990. aastate keskel hoogustunud virtuaalse reaalsuse ja virtuaalsete kogukondade uurimine põhines varasemal meediateoreetilisel ja filosoofilisel lähenemisviisil (nt Marshall McLuhan, Stuart Hall, Ronald Thomas Scollon, Suzanne Wong Scollon, Howard Rheingold, Walter Ong). Konkreetsed sisu-uurimused hakkasid ilmuma eelmise sajandi lõpul, eeskätt aga 21. sajandil, nagu Marie Laure Ryani virtuaalse narratiivsuse käsitlused (Ryan 1991, 2004 jt), Lorne L. Dawsoni ja Douglas E. Cowani on-line-religiooni ja on-line-uuspaganluse (Dawson \& Cowan 2004; Cowan 2005), Heidi Campelli sakraalsuse (Campbell 2005), Marc Smithi ja Peter Kollocki sotsiaalsete rühmade suhtluskäitumise uuringud (1999) jpm. Et viimase kümnendi jooksul on entusiastide ja heade 
arvutioskustega isikute arendatud vabaks suhtluseks mõeldud küberkeskkond tugevasti institutsionaliseerunud ja kommertsialiseerunud, on muutunud vastavalt nii kasutusalad kui ka funktsioonid. Tänased veebi kasutamise eelisalad on seotud märksõnadega e-valitsus, e-kaubandus, e-haridus, meelelahutus ja mängud, informatsiooni edastamine, e-publitseerimine, e-teenuste vahendamine. See kajastub rakenduslike ja teoreetiliste analüüside teemavalikutes - domineerivad nt veebikeskkonna kasutamine e-valitsuse huvides, poliitilise võitluse vormid veebis; vägivalla ja vihakõnega seostatud kogukondade ning nende käitumise jälgimine ja muud praktilist rakendusväärtust omavad käsitlused. Põhjalikke käsitlusi on kirjutatud isiksuse ja rühmapsühholoogia, suhtlemisstrateegiate, -võrgustike, -sageduse, aga ka formaalsete ja informaalsete suhtlusrühmade erijoonte kohta (nt Karau \& Williams 2001; Kavanaugh \& Carroll \& Rosson \& Zin \& Reese 2005; Kavanaugh \& Reese \& Carroll \& Rosson 2003; Lengel \& Tomic \& Thurlow 2004; Rodgers \& Chen $2005 \mathrm{jt})$.

On-line-kommunikatsiooni tippteemad (seksi järel) on religioon, meditsiin ja haridus, mis on esindatud sadade tuhandete veebilehtede ja arvukate diskussioonirühmadega. Neis osalejad väljendavad oma religioossust, rühmakuuluvust, opositsiooni või poolehoidu, kuid vahendavad ka teadmisi, kogemusi ja uudiseid.

Meditsiiniveebi võime jagada kaheks pooluseks: kutseliste meedikute ja erihariduseta tavakasutajate veebikeskkonnad. Professionaalide institutsionaalsed portaalid on 21. sajandil astunud dialoogi tulevaste ja praeguste patsientidega ning sisaldavad sageli laiemale avalikkusele suunatud üldist informatsiooni ja nõuandeid - terviseinformatsioon ning -nõustamine ongi kiiresti laienev meditsiiniline Interneti-teenuste liik.

On-line-meditsiinilt ja on-line-hariduselt eeldame allika usaldusväärsust ja Interneti vahendusel toimuva head taset. Muidugi valib e-meditsiini teenuste kasutaja ise, kellega ta konsulteerib, keda usaldab ja kelle nõuandeid järgib. Meditsiiniteemalistes diskussioonirühmades usaldatakse eelisjärjekorras institutsionaalseid ja garanteeritult professionaalse tasemega konsultante. Kutseliste meedikute veebikeskkonna avamine patsientidele ja terviseküsimustes võhikutele tagab patsiendile kvaliteetteenuse. Usaldusväärsete meedikute ja veebikeskkonna leidmiseks peetakse nõu oma harjumispärastes suhtlemisvõrgustikes, kuid ka meditsiinilistes diskussioonirühmades ja igapäevases veebisuhtlusrühmas.

Meditsiinisüsteemis endas tingis arvutite kasutusala ja arvutite vahendatud kommunikatsiooni laienemise eeskätt vajadus salvestada, säilitada ja töödelda patsientide andmeid. Tugevasti mõjutas arvutite kasutusala laienemist e-haiguslugude juurutamine. Siingi on arengud pidevad, nt mais 2008 avas 
Ida-Tallinna keskhaigla esimese ID-kaardiga kasutatava e-haigusloo ehk iPatsiendi portaali (BNS 2008).

Esimesed kliinikute andmebaasid ja institutsionaalsed tervishoiuveebid rajati meedikutest entusiastide ja nendega koostööd tegevate IT-spetsialistide poolt. 1990. aastate lõpus sai veebi multimeediavõimaluste arenedes e-meditsiinist Põhja-Euroopas ja Põhja-Ameerikas riigi ja suurte korporatsioonide rahastusel loodud infohaldamissüsteem ning ühtlasi oluline poliitiline küsimus. Ajaliselt langes see samasse perioodi (eriala)raamatukogude revolutsioonilise veebistamisega. Meediaanalüütik David Goodmani (2004) sõnul kiirendas eraamatukogude loomist ja digitaalsete ajakirjaartiklite e-väljaannetena kättesaadavaks tegemist biokeemia, meditsiini ja muude kapitalimahukate teadusharude kiire informatsioonivahetuse ja teadlaste koostöö vajadus.

Meditsiiniajakirjade ja vastava ametialase informatsiooni publitseerimine oli ja on kallis. See oli kommertstegevus, mille väljundeid kirjastajad ei tahtnud loovutada avalikuks tasuta kasutamiseks. E-äri laienemine tasuliste levitamiskeskkondade ja maksuliste teadusartiklite allalaadimissüsteemide suunas ning on-line-laenutuste sisseseadmine olid põhjused, mis motiveerisid arendama biokeemia- ja meditsiinialaseid veebiteenuseid. Üldiste kommunikatsioonimudelite muutumine eeldas tasuta juurdepääsu teadustulemustele. Nõudlus kasutajale avatud uue, territoriaalsetest või majanduslikest võimalustest piiramata, vaba valiidse informatsiooni järele oli suur.

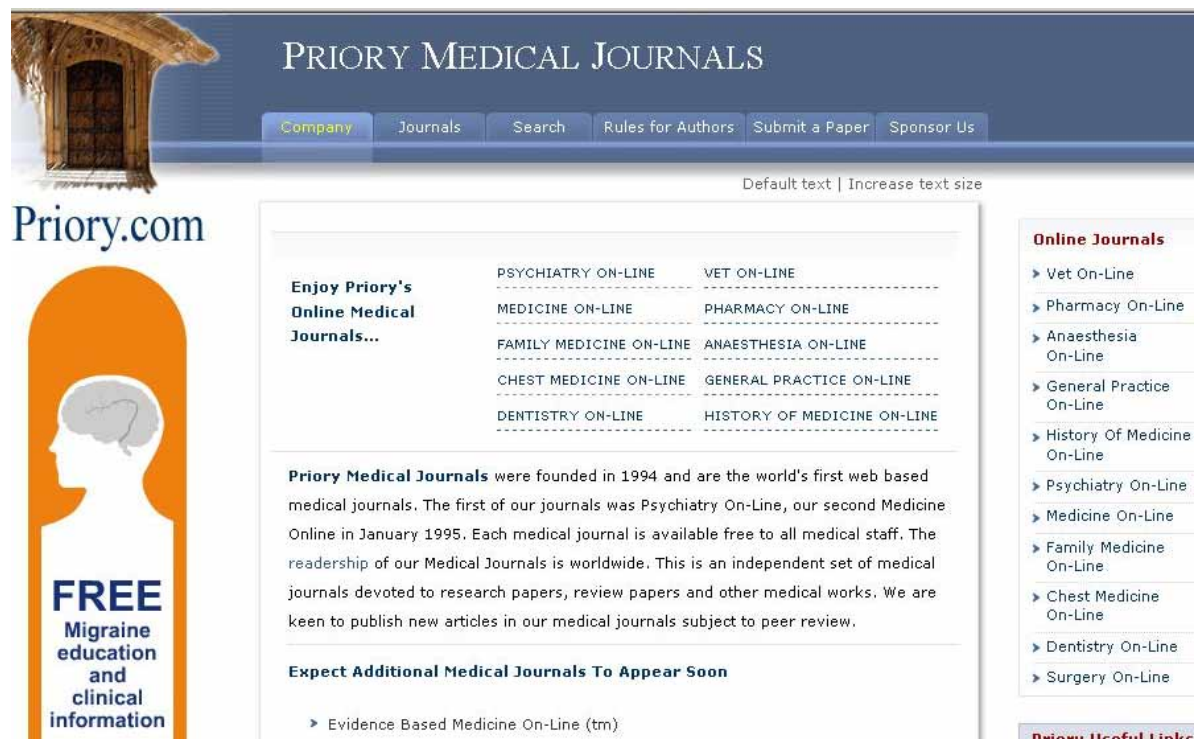

Joonis 1. 1994. aastal asutatud Priory Medical Journals hakkas esimesena maailmas koondama on-line-meditsiiniajakirju. Psychiatry On-Line ja Medicine On-line ilmuvad jaanuarist 1995 ja on meedikutele tasuta lugemiseks. 
Medscape

\section{emedicine}

\begin{tabular}{l|l|l} 
HOME SPECIALTIES REFERENCE CEnTERS & Search: eMedicine Clinical Reference, Drug Reference, MEDLINE, a
\end{tabular}

\section{Featured}

Reference Centers

Attention Deficit

Hyperactivity Disorder

Breast Cancer

Dementia

Depression and Anxiety

GERD

Herpes Zoster

HPV and Cervical Cancer

Lipid

Migraine

View All Reference Centers

\section{Infocenters}

Information from Industry

BYETAA

(exenatide)injection

Vwanse $^{\mathrm{TM}}$

(lisdexamfetamine

dimesplate) capsules

AROMASIN ${ }^{\otimes}$ (exemestane
Welcome to ehedicine - The original open access comprehensive medical textbook for all clinical fields

10,000 Contributors | 6,500 Articies

Important Imformation for Registered elMedicine Users

\section{Browse by Specialty}

\begin{tabular}{|c|c|c|}
\hline Adult Medicine & Adult Surgery & Pediatrios \\
\hline \multicolumn{2}{|c|}{ = Allergy and Immunology } & = Neurology \\
\hline \multicolumn{2}{|l|}{$=$ Cardiology } & = Obstetrics/Gynecology \\
\hline \multicolumn{2}{|c|}{ * Clinical Procedures } & $=$ Oncology \\
\hline \multicolumn{2}{|l|}{ = Critical Care } & - Perioperative Care \\
\hline \multicolumn{2}{|c|}{ = Dermatology } & = Physical Medicine and \\
\hline \multicolumn{2}{|c|}{ = Emergency Medicine } & Rehabilitation \\
\hline \multicolumn{2}{|c|}{ " Endocrinology } & " Psychiatry \\
\hline \multicolumn{2}{|c|}{$=$ Gastroenterology } & " Pulmonology \\
\hline \multicolumn{2}{|c|}{$=$ Hematology } & = Radiology \\
\hline \multicolumn{2}{|c|}{ = Infectious Diseases } & " Rheumatology \\
\hline \multicolumn{2}{|c|}{$=$ Nephrology } & " Sports Medicine \\
\hline
\end{tabular}

Joonis 2. 1996. aastal rajatud www.eMedicine.com jagab kutselistele meedikutele kliinilist informatsiooni 7000 haiguse kohta. Veebiväljundit koostaval toimetusel on abiks erialaspetsialistidest koosnevad kolleegiumid.

Üheks lahenduseks olid raamatukogudele suunatud on-line-teadusajakirjade ja -kirjanduse teenuspaketid, mille eest maksavad ülikoolid või ülikoolide raamatukogud. Ülikooli raamatukogu vahendusel sellisest paketist informatsiooni hankiv kasutaja ei pea artiklite eest ise maksma, vaid on tasuta kasutaja. Väljaspool ülikoole tegutsevatele praktikutele ja teoreetikutele selline lahendus kergendust ei toonud, kuid koos kirjastuste ajutiste tasuta teenuste kampaaniatega muutis selline informatsioonimüümise strateegia e-kirjanduse populaarseks. Kasvas digiajakirjade komplektide ja e-raamatukogude kasutamissagedus, ristviitamised ning informatsiooni levik.

Avatud teadustulemuste, sh teadusartikleid koondavate keskkondade kiire kasv on 21. sajandi erijoon ning veebi kaudu teadmiste hankimine igapäevane praktika. See asjaolu survestab omalt poolt arstiteadusliku informatsiooni avamist teadlastele ja suunanud otsima meetodeid ühiskonnaga suhtlemiseks. 


\section{Meditsiinilise informatsiooni liigid ja kommunikatsioon}

Ajalooliselt on terviseinformatsioon kuulunud spetsialistidele, arstiteaduslikke teadmisi on rangelt seostatud ametliku karjääriga. Teadmisi on kaitsnud veel kõrge hind ja teatav esoteeriline suletus. Meditsiiniteadmiste kõrvalharu ehk rahvalik populaarteadmiste võrgustik hõlmab näiteks ka laialdast ja edukat publitseerimisvaldkonda, milles ei ole tipparstid ega tippteadlased kuigi sageli osalenud. Põhjuseks võib olla muu hulgas asjaolu, et meedikute avalikkusele suunatud teadmisvood ja tegevus olid alarahastatud ja patsiendi terviseteadlikkuse kasvatamist veebiväljundite abil ei peetud veel 1990. aastate lõpus esmaoluliseks. On ka selge, et praktiseerivad arstid olid huvitatud arvutivõimaluste kasutamisest oma ametitöö huvides ja neil ei jätkunud igapäevatöö kõrval jaksu ega ressursse avaliku meditsiiniinfo loomiseks ja eksponeerimiseks.

Arvutikasutus muutis kliinikupraktikas patsiendiga suhtlemise logistikat, mis rajaneb praktilisel vajadusel ja ratsionaalselt kujundatud protseduuridel. Haiguse kulu jälgimine, arstimite leidmine, nagu teisedki arsti-patsiendi suhtlemise juurde kuuluvad seigad, hõlbustusid mõlema poole jaoks. Neil põhjustel tõsteti juba 1990. aastate keskel esile arvuti vahendatud kommunikatsiooni suuri perspektiive arstiteaduses ja arstidevahelises suhtluses:

- võimaldab erialast kommunikatsiooni;

- võimaldab meditsiini- ja multiprofessionaalsete teadmiste kasutamist;

- aitab kaasa erialakeele ja nomenklatuuri kujunemisele ja ühtlustamisele;

- võimaldab rühmatööd;

- tagab andmete konfidentsiaalsuse ja turvalisuse, kuid samal ajal ka andmete kvaliteedi ja lihtsa haldamise;

- kliinilist andmestikku on sekundaarselt võimalik kasutada konkreetse tegevuse analüüsimiseks;

- võimaldab teostada kvaliteedi monitooringuid;

- tagab uurimistöö jaoks andmestiku ja võimaldab seda efektiivselt planeerida;

- hõlbustab otsuste langetamist;

- tagab teadmiste haldamise;

- aitab pakkuda e-teenuseid väljaspool kliinikuid.

1990. aastate jooksul arenesid välja enamik suuri meditsiiniressursse, suuremaid teadmissülemeid koondati portaalidesse ja listidesse. Loodi institutsioonide ametlikud leheküljed, muutus kättesaadavaks akadeemiliste õppe- ja 
Medical Acronyms Submit Acronym

\begin{tabular}{|c|l|l|}
\hline \multicolumn{3}{|c|}{ A B C D E F G H I J K L M N O P Q R S T U V W } \\
\hline \begin{tabular}{c|l} 
Medical Acronyms \\
(Total Acronyms 462
\end{tabular} & Alphabet $A-41$ ) \\
\hline Sno & Acronym & Abbreviation \\
\hline 1 & AAA & Abdominal Aortic Aneurysm \\
\hline 2 & AB & Abortion \\
\hline 3 & ABG & Arterial Blood Gases \\
\hline 4 & AC & Anterior Cephalic vein \\
\hline 5 & ACE & Angiotensin Converting Enzyme \\
\hline 6 & ACL & Anterior Cruciate Ligament \\
\hline 7 & ACTH & Adrenocorticotropic Hormone \\
\hline 8 & ADA & American Diabetes Association \\
\hline 9 & ADH & Antidiuretic Hormone \\
\hline 10 & ADL & Activities of Daily Living \\
\hline
\end{tabular}

Disclaimer : The above utilities have been developed solely for the purpose of medical awareness and are not meant to be utilised as diagnostic tools. For precise diagnosis and prescription, Please consult a physician or a registered medical practitioner.

Joonis 3. Meditsiinisõnastikke, sh akronüümisõnastikke on portaalidesse koondatud maailma eri paikades. India akronüümisõnastik (http://www.medindia.net/acronym/index.asp) abistab tavakasutajat.

uurimiskeskuste, samuti rahvusvaheliste erialaorganisatsioonide info, eespool juba mainitud ajakirjade ja kirjanduse tutvustamise süsteem. Sellistele lehekülgedele paigutati ka tarbeinfot üldterminoloogia ja nt eritehnika kohta.

Eesti kasutajatel oli 1993. aastal olemas modemipõhine suhtlemisvõimalus (oli ka püsiühendusi - paar aastat varem Tartu Observatooriumil Tõraveres ja Keemilise Biofüüsika Instituudil Tallinnas, hiljem ülikoolides, aga ka Postimehes jt päevalehtedes) ning esimesed ASCII-põhised lihtsad linkidega veebileheküljed (Sein 1998). Olulisem informatsiooni koondamine Internetti algas 1990. aastate keskel ning arenes entusiastide algatusel ja riigi toetusel väga kiiresti. Tänane tervist ja haigust, arstiteadust ning arste puudutav veebiinformatsioon on mitmekülgne. Riigi e-kodaniku teenindusportaal (www.eesti.ee) informeerib inimesi nende tervisega seotud kohustustest ja õigustest, tervisekindlustusest, meditsiiniabi saamisest ja õiguslikest aktidest. Riigi toetusel rajatakse üleriigilist integreeritud e-meditsiini teenuste süsteemi, võimaldamaks arstidel vahetada igasugust tervist puudutavat andmestikku. 


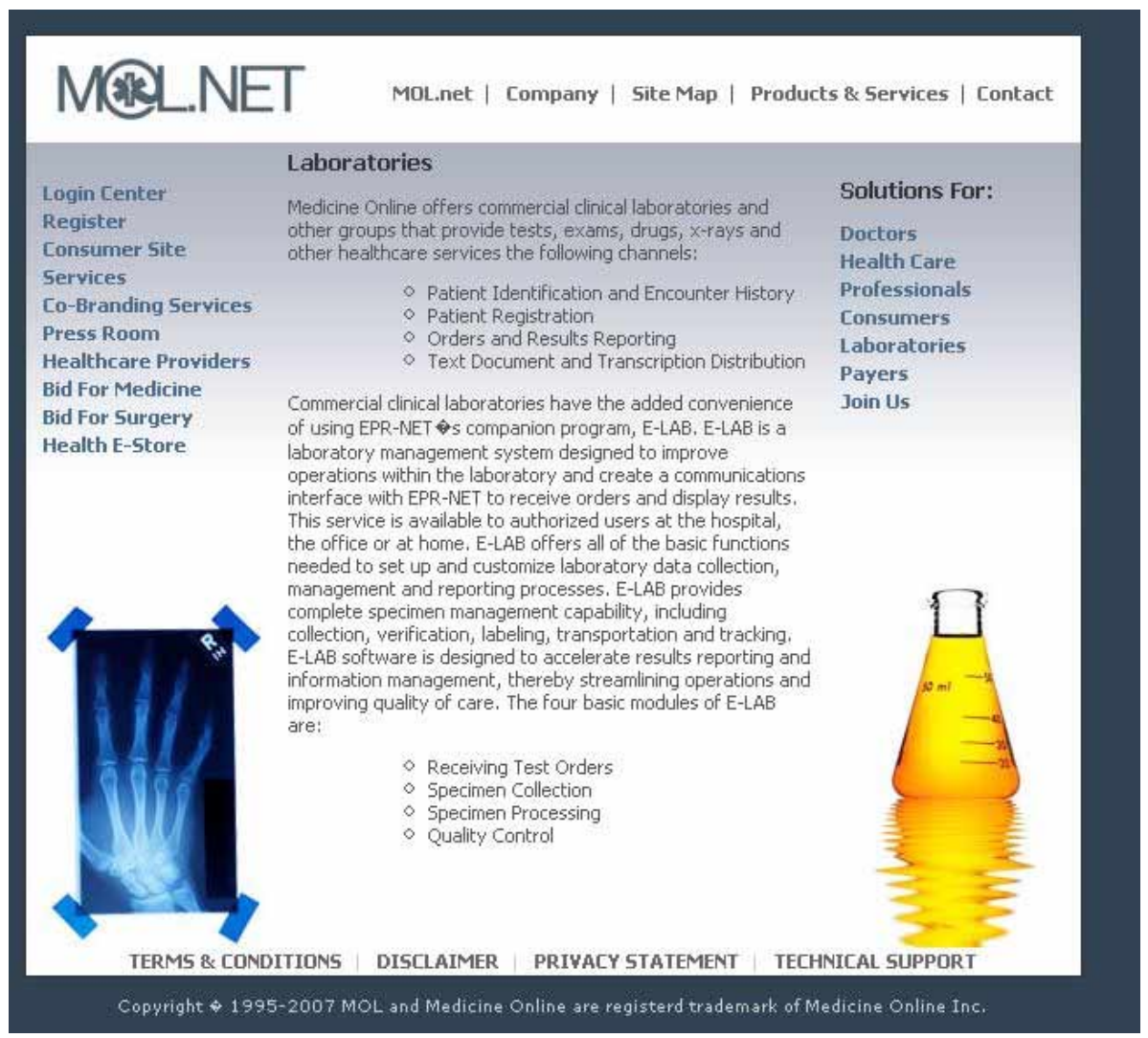

Joonis 4. California Medicine Online Incorporated portaal www.MOL.net rajati 1995. aastal. 1999. aastast saab selle kaudu otsida endale sobivat arsti, ravimeid, teha analüüse. 2000. aasta märtsist toimivad innovatiivsed Bid For Surgery ja Bid For Medicine abistavad patsiente ka nt teabega eelseisva operatsiooni kohta ja võimaldavad võrrelda protseduuri hindasid erinevate meedikute juures.

Suuremad meditsiiniportaalid lähtuvad erinevast informatsiooni edastamise loogikast. Arst.ee (www.arst.ee) on professionaale ja nendega seotud asutusi vahendav portaal. 2005. aastast avatud on-line-nõustamise võimalus kogub üha populaarsust. Arst.ee sisaldab avalehe teatel teavet 13001 meditsiinitöötaja, 1506 asutuse, 2559 ravimi, 35 haiguse kohta (www.arst.ee). Alternatiivne portaal inimene.ee (www.inimene.ee) tutvustab perearste.

Esimene ametliku meditsiini esindajate koostatud ja mittemeedikutele, eeskätt patsientidele suunatud teabeportaal kliinik.ee (www.kliinik.ee, OÜ Tervisenõuanne) pakub patsientidele autoriseeritud informatsiooni konkreetsete haiguste kohta, tutvustab kompleksseid e-teenuseid, kajastatab uusi erialaraamatuid ja ravimeid, nõustab dieetide ning toitumise osas; portaal teenin- 
dab ka diskussioonirühmasid. Patsiendil on võimalik jääda kliinik.ee keskkonnas soovi korral anonüümseks, kuid paljud eelistavad märkida eesnime ja vanuse. Osa informatsiooni on saadaval väikese tasu eest (http://www.kliinik.ee/ index.php?4).

Mõlemad suured portaalid (arst.ee ja kliinik.ee) edastavad patsientidele erialaarstide, psühholoogide ja raviminõustajate vastuseid ja uudiseid, on linkinud kasulikke artikleid, intervjuusid, terviseteste ja arutelusid. Kliinik.ee sisaldab lisaks huumorinurka ja küsitluste osa ehk siis laiemat nõuannetepa-

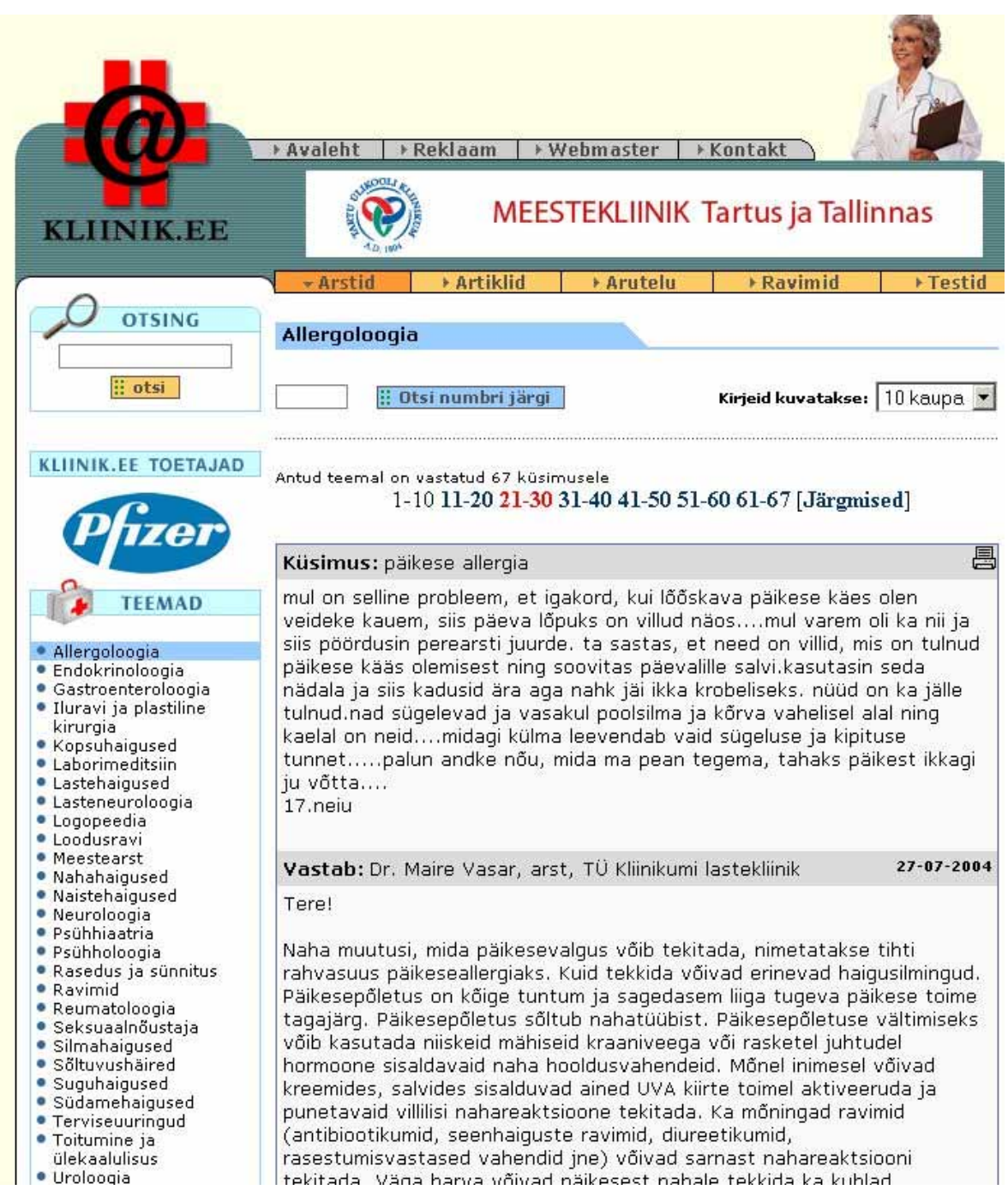

Joonis 5. Kliinik.ee keskkonnas saab küsida eksperthinnangut oma haiguse ja ravimite kohta. 
ketti, samas võimaldab maandada haigustega seotud stressi. Varasemaid küsimusi ja vastuseid saab lugeda külgmenüüs toodud teemade alt, need annavad ülevaate haiguse kulgemisest, raviviisidest ja sümptomitest. Menüüst Arutelu (foorumi ehk vabaarutelu paik) leiab aga kasutajate suhtluse tervist puudutavatel teemadel. Väärib märkimist, et foorumite temaatika on kitsam kui konsultatsioonide oma, ka sarnaneb see suhtlustasemelt ja keelevalikult Delfi ja muude uudisteportaalide temaatiliste diskussioonirühmadega. Oma veebikeskkonnad on konkreetse haigusega seotud liitudel ja seltsidel (nt Eesti Vähiliit)

Meditsiinilise teeninduse eriliikidest tuleb märkida eraldi veel administratiivse ravikorraldamise, arstiteenuste ja perearstidega suhtlemise mooduseid, e-diagnooside ja e-ravimiteabega seotud teenuseid.

Eesti suurim regionaalkeskus Tartu Ülikooli Kliinikum teenindab peaaegu 500000 inimest ehk umbes kolmandikku riigi elanikkonnast. Viimastel aastatel on kliinik spetsialiseerunud Lõuna-Eesti patsientide abistamisele, kuivõrd tegemist on olulise teaduskeskusega, pöördutakse sinna keeruliste juhtumite puhul kogu Eestist (http://www.kliinikum.ee/index.php?mod=mainpage).

On-line-registreerimise võimalused on 21. sajandil kõigil suurtel kliinikutel ja see hõlbustab patsiendi teenindamist, sest telefonitsi või isiklikult registreerimas käimine on ajakulukas, telefoniteenuse ooteajad on üldjuhul pikad.

Perearstid teenindavad kindlat registreeritud patsientide hulka, keskmiselt kuni 2000 isikut (www.perearstikeskus.ee), nende ülesanne on esialgse diagnoosi määramine, üldhaiguste ravimine, tervisenõustamine, abi haiguste ennetamisel ja eriarstide vahendamine. Tänaseni on vaid üksikutel perearstidel oma veebilehekülg, patsientidega suhtlevad nad nii telefonitsi kui ka e-mailitsi. Kuigi valitud vorm sõltub arsti harjumustest, eelistatakse pigem telefonisuhtlust. Nähtavasti on üks põhjusi vahetu kontakt ja suhtlemise turvalisus, kindlasti aga ammu tuntud tõsiasi, et inimene räägib palju kiiremini kui kirjutab, mistõttu telefonivestlus hoiab kokku mõlema osapoole aega. Alahinnata ei saa ka suulise kontakti vahetut rahustavat mõju patsiendile.

E-mail on levinud administratiivse ja formaalse informatsiooni saatmiseks, nt analüüsitulemuste teatamiseks. Haigustega seotud teabe saatmine perearstilt patsiendile on harv erand, eelistatum suhtlusvorm on silmast silma kommunikatsioon.

Patsientidel on õigus saada oma tervise kohta teavet ja täiendavat hinnangut sõltumatult meedikult. Sellist võimalust pakub on-line-teenusena pikemat aega keskkond kliinik.ee, mille mõjul on viimasel ajal ka portaal arst.ee laiendanud on-line-diagnoosimise teenuseid ja pakkunud hinnangut määratud ravimisviisile. 
On-line-ravimiteave jaguneb mitme portaali vahel, kuid veebi kaudu ravimite müümine ei ole Eestis levinud. Traditsioonilised ravimtaimed on vähesel määral tellitavad taimekasvatajate lehekülgede vahendusel, samal ajal ravimeid müüakse üldiselt üksnes apteekides. Toidulisandid ja salenemisvahendid on müügil ka (osaliselt isegi ainult) on-line-kataloogide või kodulehekülgede kaudu.

Kõikvõimalikku teavet ravimite ja nendega seonduvate seaduste kohta pakub oma koduleheküljel Ravimiamet (http://www.ravimiamet.ee). Apteekide Infotehnoloogia OÜ haldab lehekülge raviminfo.ee, mille ülesanne on abistada patsiente ja arste. Sellel leheküljel saab tutvuda ravimite hindadega kõigis Eesti apteekides, leida hinnalt ja omadustelt sobivaimat ravimit ning tutvuda väljakirjutamise tingimustega, samas leidub ka ravimite koostoimete andmebaas (http:// www.raviminfo.ee). Loendi farmaatsiaalase informatsiooni leidumisest Internetis on koostanud

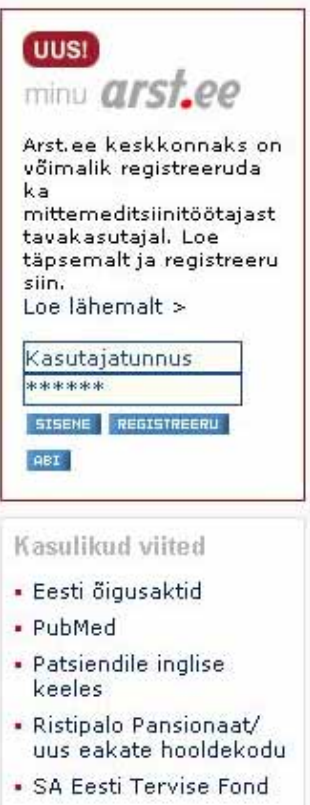

Joonis 6. Arst.ee kutsub oma keskkonda rajama ka mittemeedikuid.

Tartu Ülikooli Farmaatsia Instituudi töötajad Ain Raali eestvõtmisel (http:// www.ut.ee/ARFA/interfar.htm).

21. sajandil esitlevad arstide ühenduste veebilehed organisatsioonilise teabe kõrval ka eriala ajaloo diskursust: kirjutisi ametiala ajaloost ja alusepanijatest, programmilisi pöördumisi ja tagasiside-liideseid (vt nt Eesti Ämmaemandate Ühing, http://www.ammaemand.org.ee/index.php?id=387). Ka on veebiportaalides kasvanud professionaalidele suunatud koolitus ja enesetäiendamisteabe osa.

\section{Suhtlusrühmad ja meditsiiniinfo vahetamine}

Nüüdisühiskonda iseloomustab keelte, kultuuride, etniliste, konfessionaalsete ja muude rühmade heterogeensus. See on arenenud kindlates ajaloolistes, sotsiaalpoliitilistes, ideoloogilistes, demograafilistes ja majanduslikes tingimustes. Virtuaalset reaalsust iseloomustab samasugune rühmade heterogeensus. Seal toimuvad protsessid võimaldavad konstrueerida, reprodutseerida ja transformeerida identiteete, väärtus- ja enesehinnanguid ning narratiive. Näib, et globaliseeruva maailma põhilised tunnused kehtivad ka küberruumis. 


\title{
Harvard Medical School
}

\section{Department of Continuing Education}

HOME

MY CME

COURSE LIST

ABOUT US

SITE MAP

\section{Continuing Medical Education Online for Physicians and Other Health Professionals}

\author{
"Learning is a Lifelong Privilege. Pursue it with passion and zeal, \\ and watch the wonder fill your world." \\ -- Sanjiv Chopra, MD
}

Welcome to Harvard Medical School Department of Continuing Education online. Online CME is a tool enabling HMS Faculty to come to the homes and offices of health care professionals throughout the world, helping make the pursuit of life long learning accessible and affordable.

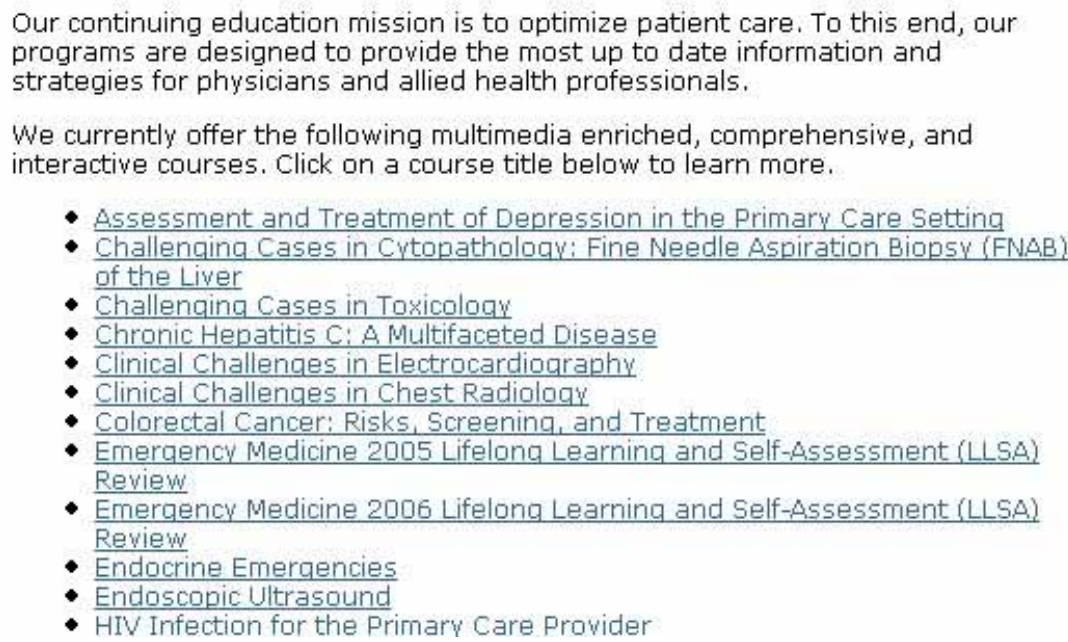

Joonis 7. Kutseliste meedikute jätkuõpingud on osa tänasest meditsiinikultuurist.

Hilisuuringud on osutanud kasvavale kogukondlike suhete erosioonile, isolatsiooni kasvule, fragmentatsioonile, eemaldumisele teiste eest vastutamisest reaalses elus. Selle alusel on osutatud ühtaegu inimeste vähenevale poliitilisele, ühiskondlikule ja religioossele osalemisele, vabatahtliku abi vähenemisele ning ühtlasi asjaolule, et 90 protsendil täiskasvanutest on sotsiaalsed suhted seotud oma töökohaga (Putnam 2000, sama ka Shklovski \& Kraut \& Rainie 2004). See tähendab olulist inimlike suhete vaesustumist ja tugiisikute kadumist. Kerkib küsimus, kas Interneti-kogukonnad järgivad sama tendentsi või 
hoopis asendavad sealsed sotsiaalkultuurilised suhted endist tsiviil- ja perekondlikku suhtlemist? Või on tegemist täiesti teisenenud suhtlemismudelitega?

Indentifitseerimis- ja kategoriseerimisprotsess eeldab kollektiivset kohesiooni, integreerumist ja teisest rühmast eristamist, mis on mõistetav kindlas ajaloolises kontekstis ja situatsioonis. Interneti-suhtluses võivad kaks isikut olla ühendatud omavahelise sidemega, üksikisik võib olla kahe või enama rühma liige. Selline osalemine vormib rühmadevahelisi sidemeid. Kaudselt on ühendatud kõik erinevate rühmade liikmed, aidates kaasa rühmadevahelisele informatsiooni- ja pärimusvoogude liikumisele. Seesugune silla loomine (bridging) rühmade vahel, täiendatuna rühma sees valitsevatest sidemetest, loob olulise sotsiaalse kapitali.

Interneti-kogukondades ja -kommunikatsioonis osalemiseks on erinevad motivaatorid ja funktsioonid. Näiteks on Andrea Kavanaugh, Debbie Denise Reese, John M. Carroll ja Mary Beth Rosson (2003) osutanud, et mitme veebirühma vahel sildadena toimivad inimesed on tavaliselt aktiivsemad ka kohalikus kogukonnas, Internet on neile tihti vahend oma hõivatuse säilitamiseks ja selle hõlbustamiseks. Steven J. Karau ja Kipling D. Williamsi (2001) järgi võib motivaatoriks olla kollektiivne edu, kuid seda juhul, kui see toetab individuaalset edukust. Paljude kogukondade liikmete puhul on jälgitav isiku- või rühmaidentiteedi loomine. Richard Jenkins (1996) kirjutab:

Enesenägemus on "pidev ja tegelikkuses samaaegne (sisemise) enesemääratluse ja teistelt saadud (väliste) enesekohaste määratluste sulandumise protsess" ning sellest iseduse mõistest tekib kahe erineva piirkondliku lõimega identiteediloome mudel.

Kui arvestada, et individuaalne identiteet konstrueeritakse sotsiaalselt suheldes, sotsiaalses interaktsioonis, mille käigus ennast nii määratletakse kui ka hinnatakse ümber ja määratletakse uuesti oma elukogemuse põhjal, siis on see põhjus, miks liituvad kindla foorumi või temaatilise rühmaga trauma, haiguse, diskrimineerimise üle elanud või kriisiolukorras viibijad.

Meditsiinialane informatsioongi liigub veebis lisaks ametlikele institutsionaalsetele kanalitele erinevas vormis ja suhtlemiskeskkondades ehk juba eespool viidatud jututubades, isiklikel veebilehtedel, e-ajakirjanduses, seltside ja organisatsioonide lehekülgedel jm. Oma veebileheküljed on ka mitmel alternatiivmeedikul ja alternatiivmeedikute ühendustel, mis muudab veebivalikud sama kirevaks kui reaalse elu võimalused.

Patsiendile annab veebikeskkond ja -suhtlemine lisaks meditsiiniinformatsioonile ning raviskeemi ja haiguse sõltumatule ekspertiisile võimaluse esine- 
da ise eksperdina, vahendada oma haiguskogemusi ja saada kinnitust asjaolule, et temaga toimuv kuulub normaalsuse skaalasse. Arthur Kleinmani järgi on see põhiküsimus nagu ka valus küsimus - miks see juhtus minuga (Kleinman 1980). Muutunud sotsiaalsed olud ja urbaniseerunud keskkonnas levinud väikeperede mudel tähendab, et lähisugulased elavad suurte vahemaade taga. See soosib (mõtte)kaaslaste otsimist töökaaslaste seast ja virtuaalsest keskkonnast. Diskussioonirühmad asendavad silmanähtavalt mingis osas kunagist perekonna või territoriaalse rühma osa haiguste ja tervise üle arutlemise ning lahenduste otsimise diskursuses. Et postmodernistlik eluviis ja tõlgendused tunnistavad erinevaid teadmisi ning on orienteeritud subjektiivsusele, vastab nt diskussioonirühma arvamuste vastuoluline paljusus hästi moodsale stiilile. See vastandub mitmel viisil ratsionaalsele objektiivsuse suunas püüdlevale molekulaarbioloogia ja biokeemiaga tihedalt seotud tänapäevasele ametlikule meditsiinile.

Väga oluline on kogemuslike trauma- ja haigusnarratiivide esitamise ja vahetamise võimalus, mis sellise kogemuse kandjal või üleelanul oma lähemas ümbruses sageli puudub. Kuigi lähemad sugulased ja sõbrad taluvad lühemat aega korduva haigusnarratiivi esitamist, on see neile psühholoogiliselt raske kogemus, millega ei osata kohaneda. Töökaaslaste seas leidub sageli neid, kes kaitsevad end rusuvate elamuste eest ega ole empaatilised teise inimese haiguste ja kannatuste suhtes. See võib viia haige traumeerimise ja kogukonnast välistamiseni või drastilisematel juhtudel töökoha kaotamiseni. Näiteks kaebasid mõne aasta eest Tartus paar kõrgharidusega filoloogi direktorile oma raske tervisehäire üleelanud kolleegi peale, et see ahistab neid oma meenutuste ja arutlustega. Kogu juhtum kulmineerus peapesu ja ähvardustega direktori juures. Suhtlemiskriis lahendati administratiivselt ülalt alla teatud teemadel vestlemise keeluga haigele, säästmaks kolleege kokkupuutest frustreeriva põdemine-haigus-kannatused-diskursusega.

Raske või fataalse haiguse põdejate veebifoorumid aitavad haigestunutel üksteist moraalselt ja mentaalselt toetada, diagnoosida oma tervislikku seisundit, vahetada kogemusi haiguse leevendamise suhtes, vahendavad tervenemisjuhtumeid, õpetavad toimetulekustrateegiaid ja - taas kord - aitavad üle saada küsimustest teemal, miks just mina haigestusin. Aina laiemalt on levinud raskete haigete nn kirjutamisteraapia, mille spontaanne haru areneb veebis. Diabeetikute, vähihaigete ja muude ravile halvasti alluvate või allumatute haiguste põdejate foorumeid leiab tänapäeval kõikjal. Veebikeskkonnal on siinjuures mitmeid eeliseid, näiteks ei ole see monoloog, vaid siiski dialoog sarnases olukorras viibivate isikutega. Samas on soovi korral võimalik säilitada oma isiklik privaatsus ja anonüümsus. 


\section{Suhtlemine meditsiiniveebis}

Eelnevast järeldub, et on-line-suhtlemise situatsioonis erineb - sõltuvalt valitud rühmast ja keskkonna iseloomust - keelekasutus, suhtlusakti ülesehitus, pikkus, keerukus ja erinevate stiilide kasutamine. Suhtluskoodide vahetamise määrab partnerite motivatsioon, kuid ka keskkonna iseloomu tunnetamine. Kui patsient otsib abi ametliku meditsiini esindajalt institutsionaalse lehe vahendusel, on suhtluskood ja -keel formaalne ja viisakas ning säilitab asjaliku tõsise tooni. Nagu märgitud, tagavad ametlikud foorumid patsiendile anonüümsuse, kuid arsti nimeline vastamine suurendab eksperthinnangu usaldusväärsust.

Näide ametlikust foorumist:

Katrin kardioloogia 24.02.2008

Kõrge vererõhk

Olen 23-aastane naine. Mul on olnud juba umbes 8 aastat kõrge vererõhk (100-115/134-170). Olen teinud kõikvõimalikke uuringuid (südame-, neeru-). Kõik tundub korras olevat. Ilmselt on see pärilik (isal on ka). Ravimeid tarvitada ei tahaks. Olen teadlik ka tervislikest eluviisidest (sport, kehakaal, toitumine jne.), kuid need ei aita alandada vererõhku. Mida oleks võimalik siiski ise teha et vererõhku normis hoida? Kui kaua peab keha vastu kõrgele vererõhule? Millal siis võivad tekkida tüsistused (veresoonte lupjumine, trombid jne.)?

Ette tänades Katrin

Vastab: Märt Elmet 25.02.2008

Tere,

Sellised vererõhu väärtused on liiga kõrged, millelele tuleb kindlasti reageerida.

Kõrgvererõhu tõve jaoks olete väga noor ja seetõttu peaks arstid väga hoolikalt uurima, millest kõrge rõhk on tingitud. Võimalikke põhjuseid on palju ja sageli on neid raske leida.

Kõrge vererõhk hakkab oma hävitustööd tegema kohe. Ühel hetkel jõuab organite kahjustus lihtsalt kriitilise piirini ja tekitab tõsiseid tervisehäireid. Paraku võib kõrgvererõhutõve esimene tüsistus olla invaliidistav või surmav (näiteks insult), seega peab probleemiga tegelema kohe.

Ravi saab määrata siis, kui uuringutega on selgeks tehtud, mis organismis valesti toimib.

Märt Elmet 
evelin kardioloogia 19.02.2008

valud rinnus

Tere, olen 28-a. naine. Mure järgmine: peale teise lapse sündi (2007 nov.) tekkisid rindkere valud, mis kiirguvad nüüd ka vasakusse kätte, selga ja ka kaela. Õrn valu on pidevalt seljas, õlas ja käes ja siis aegajalt lööb tugeva, terava valu rindkeresse, mis kiirgub kergelt õlga (valu kestab u. 3-5 sek.) Perearstilt sain rohu Preductal, mida nüüd võtangi. Kuid tahaks ikkagi selgust saada, millest sellised valud? Äkki polekski seda rohtu hea võtta ja mille puhul seda üldse võetakse? Mida teha?

Vastab: Märt Elmet 25.02.2008

Tere,

Kirja teel ei ole mul võimalik täpsustada, millest valud on tingitud. Noortel inimestel on rindkerevalud sageli seotud kroonilise närvi- või lihaspõletikuga. Ka muud põhjused võivad arvesse tulla, kuid need peaks perearst selgeks tegema.

Preductal on ette nähtud südamelihase ainevahetuse parandamiseks veresoonte ateroskleroosi korral. Teie olukorras ta ilmsel[t] olulist toimet ei oma.

Märt Elmet

Mõlemad kirjutajad eeldavad sõltumatut eksperthinnangut ning nende keelekasutus on formaalne. Seda iseloomustavad keelendid, mida kõnekeelest ei leia, nagu 'rindkere' või 'tekkida võivad tüsistused' ja 'sümptomid'. Haiguskirjeldust iseloomustab täpsusetaotlus. Selline objektiivsusele pretendeeriv kirjalik narratiiv on lähedane suulisele patsiendi-arsti narratiivile, ainult et dialoog ei arene, vaid on fikseeritud ja piirdub ühe suhtlemisepisoodiga. Arst ja patsient lähtuvad erinevast kognitiivsest mudelist ja esindavad mitte võrdseid, vaid erinevaid sotsiaalpoliitilisi huvisid (vrd Kleinman 1980; Singer \& Baer 1995: 375). Ühe tarvidus abi järele ja teise võim abi anda väljendub narratiivi keelekasutuse kõrval selle üleehituses, mille juurde kuulub teretamine ja tänamine, vanuse ja soo määratlemine (ehkki viimane selgub eestlastel enamasti juba eesnimest), diagnoos, haiguskirjeldus, määratud ravimid, küsimused haiguse kulgemise ja ravimite kohta. Arsti neutraalses keeles vastus iseloomustab haigusnähtusi ja ravimeid. Ekspertiisi kõrval on arsti narratiivi ülesanne anda nõu ning hoiatada väärsammude ja ohtlike olukordade eest.

Kindla haiguse põdejate või patsientide foorumis suheldakse vabamalt ja need sisaldavad väga erinevaid jutustamisvorme ja kirjutamisstiile. Huviväärsed on siinjuures nii konkreetsetes foorumites arendatavad arutelud haiguste, ravi kui ka alternatiivmeedikute üle, mille kohta esitan näitetekstina kat- 
kendid diabeetikute foorumi arutelust ravija Viktori teemal. Viktor on tegutsenud ravijana alates 1980 . aastatest ja teda on tutvustatud ka meedias, mistõttu on temaga kokkupuutunuid või tema kohta midagi kuulnuid palju. Diskussioon moodustab ühtse narratiivse terviku, millele erinevad osapooled lisavad isiklikke repliike ja lugusid. Käivitajaks on ühe foorumi liikme lugu lapse isa käigust ravija Viktori juures ja küsimus visiidi mõttekusest.

01.02.2005 15:25

Mu lapse isa käis lapsega ravitseja Viktori (Tallinnast) juures ja see olla mingit ravimit kirjutanud (enda toodetud).

Ma kohe mitte ei julgeks seda umbkaudu lapsele sisse sööta... kas keegi on ehk kuulnud ravitseja Viktorist midagi???

Pidavat maailmakuulus olema???

Käesolevasse narratiivsesse tervikusse kuuluvad arutelud rahvaarstide ja arstide, uskumise ja usaldamise teemal, informeerivad teated, ekspressiivsed hinnangud, haiguse tõsidust kinnitavad lood, kirjeldused kokkupuuteist rahvaarstidega. Eendub didaktiline hoiatav ja meditsiini eelistav diskursus.

Vihane anonü̈̈mne, 01.02.2005 15:56

Ma ei taha kelleltki lootust ära võtta, aga kui keegi on kuulnud mõnest ravitsejast, kes surnuid oskab ellu äratada [,] ja teab ka mõnd juhtumit [,] kus on kegai [kedagi] äratatud surnuist, siis seda posijat ma prooviks ka ise...

Kuna see on aga ilmvõimatu (surnute elluäratamine[,]) siis pole mõtet ju proovida.

Küll võib proovida kõike seda jama II tüübi diabeetik.

Need posijad, kes lubavad ravida I tü̈̈bi diabeeti[,] ei tea diabeedist tuhkagi[,] ja need, kes oma lapsega sinna lähevad[,] samuti mitte.

01.02.2005 16:02

Ega ta vist lausa välja ravida polevatki lubanud, aga muidu seisundit parandada??? Ja olevat veel öelnud, et kilpnäärmega pole ka kõik korras.

Aga ma ei tea jah, ei tahaks ikka usaldada.

01.02.2005 18:07

Tere,

Tea, kas on tegemist sama n.ö ravitsejaga, aga kellestki samanimelisest olen kuulnud aastaid. Kord pakkus heausklikele mingeid "imesid tegevaid pilte”, et vaatad ja saad oma ihuhädadele leevendust. Ei oska kommentee- 
rida sellise ravimeetodi tulemuslikkust, kuid julgen sügavalt kahelda positiivses tulemuses.

Igatahes ei tasuks neid imearste usaldada. Aga loomulikult nad kiidavad oma "ravimite" ja "ravimeetodite" efektiivsust, sest muidu ju keegi nende juurde ei tuleks ja kust nad siis raha saaksid.

Mirka

\subsubsection{0:54}

tere. $k$ a midagi positiivset. minu ühe tuttava isa ta küll aitas. see mees kanti maha arstide poolt. lõigati lõhki ja öeldi [,] et siin ei ole enam midagi teha, maksas oli kasvaja. see viktor õpetas, mida ja kuidas teha [,] ja uskumatu, ta paranes ja elas veel 5 aastat [,] aga siis suri kõrge veresuhkru tõttu.

02.02.2005 15:30

mingit $x$ sodi ei julgex mina küll lapsele anda. mina olen lapsest saati diabeetik ja minu vanemad vedasid mindki mingi ravitseja juurde. andis $k a$ mingit rohtu, võtsin mõned korrad, siis keeldusin, vanemad sundisid, ei võtnud. asi lõppes haiglas. PALUN, ÄRGE TEHKE OMA LAPSELE HALBA MINGITE SODIDEGA - MINGE ENDOKRINOLOOGI JUURDE SEAL KONTROLLITAKSE KA KILPNÄÄRET. Ma saan aru[,] et see on lootus, aga teie laps ei hakka kaugeltki surema. aidake teda enesekontrollis ja olge toeks. KÕIKE HEAD TEILE! KAKUKE.

\subsubsection{8:51}

Soovitan mitte selliste asjadega tegeleda. Kui diabeet on kompenseeritud, veresuhkrud stabiilselt kenad koos kohatiste ja loomulike kõikumistega-siis ongi olukord hea. On kogemusi mitmesuguste ravitsejatega ja üks mis kindel: keegi neist ei tea midagi diabeedist ega ühestki muust kroonilisest (vbla ka mitte muust) haigusest. Diabeedi kohta on isegi paljudel päris arstidel igasugused kummalised arusaamad, mis siis veel "ravitsejatest" rääkida. Kilpnäärme torkas ta kindlasti sellepärast juurde, et mõjusam oleks, et häda rohkem - tulu rohkem. Häbematud inimesed sellised soolapuhujad.

08.02.2005 08:25

Jah, sai "ravim" tagasi saadetud.

Aitüma kõigile, kes vastasid. Arvasin ise ka kohe algul, et ei tasu jamada (aga noh, lapse isa oli usku ja väge täis).

Eriti huvitav oli see jutt, mis laps eile rääkis... et kui nad isaga seal vastuvõtul käisid, siis ravitseja olla öelnud, et praegu on v/s 20 ringis, aga 
ma võtan kohe alla... siis kripseldanud midagi paberile ja öelnud, et nü̈̈d on umbes 4... laps siis öelnud, et vot kui tore, ma lähen koju ja mõõdan kohe... siis ehmatanud nagu ära ja küsind, et kus sa elad... laps siis öelnud (mingi 2 km)... siis "ravitseja" vastanud, et see ju nii "pikk" maa ... selle aja peale võib uuesti tõusta... IRW!!!!... Kahju, et laps seda intsidenti enne ei kirjeldanud, ma oleks kohe teadnud, kuidas talitada.

Arutlus toimus kaheksa päeva jooksul (esitasin sellest valikulisi väljavõtteid), loo rääkija kulmineerib selle lapselt kuuldud jutuga ravija juures toimunust, mis aitab ema seisukohta kinnitada. Järgnevad mitmed kaasfoorumiliste lühemad (siunavad) kommentaarid. Viktor arstijana kerkib uuesti arutlusobjektiks teise nurga alt umbes nädal hiljem ja veel ka kuu aja pärast, kuid siis püsib huvi mõned päevad. Järgmiste episoodide lühidus on arvatavasti tingitud asjaolust, et puudub intrigeeriv tegelik sündmus, lugu, mis kutsuks arutlema, vaid tegemist on eeskätt informatsiooni vahetamisega. Diskusiooni veebruarist aprilli alguseni kestnud diskreetne joon toob esile erinevaid kognitiivseid lähenemisviise, narratiivsust, argumentatsiooni ja kogemusi ning on sellisena huvitav analoog suulisele mitme osavõtjaga dialoogile. Mõlemal juhul on tegemist arvamuste paljusust esile toova suhtlusega, mille käigus sõlmitakse leppeid ja esitatakse olukorra kohta oma eksperthinnanguid.

Ametlikus portaalis suheldakse ravijatega (nt Vigala Sassiga suhtlemine kliinik.ee-s) samuti kui diplomeeritud meedikutega ehk siis viisakalt ja formaalselt. Muudes avalikes veebikeskkondades varieeruvad keelekasutus ja suhtumised tugevasti, ulatudes aupaklikust ja austavast, aktsepteerivast, humoorika, uudishimuliku, närvilise, eitava või järsult vastuseisva stiilini.

Küll aga väärib märkimist, et on-line-intervjuud rahvaarstidega toovad esile samu tendentse, mis ilmnevad reaalses elus teadjat külastavate isikute puhul: nendega soovitakse arutada paljusid küsimusi, mis ei ole otseselt seotud meditsiiniga. Neid käsitletakse laiade teadmistega usaldusväärse eksperdina, isikuna, kelle arvamust tahetakse teada (Kõiva 1995; 2008).

Meditsiinifoorumites levib narratiivide kõrval üsna sageli ka folkloorseid uskumusi. Üks efektne näide on seotud mobiiltelefonidega, mille ümber on nende müüki saabumisest alates levinud folkloor tervisekahjulikkusest, vähi tekitamisest, aju küpsetamisest ja kõrvakuulmise halvendamisest. Seda probleemi on tutvustanud tuntud Saksa folklorist Sabine Wienker-Piepho artiklis "Mobiiltelefonijutud ehk mobiiltelefonipärimus" kogumikus Meedia. Folkloor. Mütoloogia (Wienker-Piepho 2000, vt http://www.folklore.ee/pubte/meedia). Samalaadset ainestikku on analüüsinud on-line-meditsiini seisukohast juba eespool viidatud poliitika ja kommunikatsiooni uurija Kay Richardson oma raamatus Internet Discourse And Health Debates (Richardson 2005: 53 jj), osuta- 
des erinevate meediakanalite mõjutustele suulisele/kirjalikule Interneti-pärimusele.

\section{Kokkuvõte}

Suurim muutus on aset leidnud kahtlemata ametliku meditsiini suhtumises terviseteabesse, mittekutselistele isikutele täiendusõppe pakkumisse ja nende informeerimisse uuematest teadustulemustest. Tunnuslik on meditsiiniportaalidesse suhteliselt laiapõhjalise informatsiooni koondamine ja uuendusena isiklike keskkondade loomise võimaluste pakkumine ka mitteprofessionaalidele, sh patsientidele.

Meditsiiniinformatsiooni ja tulemuste laiapõhjaline tutvustamine ametlikus usaldusväärses keskkonnas tõkestab kindlasti vähemalt osaliselt kuulujutte, stereotüüpe, linnamuistendeid, kõmu ja arhailisi narratiive, mida edastatakse omavahelises kõnes suuliselt, kuid mis levib ka mitmete meediakanalite vahendusel. Loomulikult leidub selliseid motiive ja arutlusi suhtlusrühmades ja foorumites, mille narratiivne sisu ja folkloorsed sugemed on mitmetasemelise ja 'paljuhäälse' kommunikatsiooni näide. Meedikutele mõeldud ja meedikute loodud keskkondade põhjal on selge, et suhtlemine arsti ja patsiendi vahel järgib on-line-keskkonnas samu reegleid kui suulise silmast silma suhtlemise puhul. Seda iseloomustab teatav distantseeritus, viisakus, ametlikkus, objektiivsusetaotlus ja narratiivi ökonoomsus, kuivõrd suhtlemisepisood on ajaliselt piiratud. Seevastu meditsiiniportaalide diskusioonirühmade suhtlemisstrateegiad on märgatavalt avaramad ning nendes osalejad kasutavad individualiseeritud stiili ja esindavad erinevaid suhtumisrühmi. Dialoog areneb läbirääkimiste, argumenteerimise, eksperthinnangutele toetumise ja muude taktikate abil.

Omaette küsimus on, kas sellised meditsiini või konkreetse haigusega seotud kooslused kujutavad endast kogukonda, sotsiaalset võrgustikku. Ilmselt mitte, sest tegemist on sageli tingliku rühmaga, kes ei moodusta tingimata kogukonda, vaid kes algatavad dialoogi eksperthinnangu hankimiseks või oma hinnangu lisamiseks. Külastused on ajendatud vajadusest ja võivad olla ühekordsed. Patsientide ja põdejate diskussioonirühmade liikmetel ja nende narratiividel on tihe side tegelikkusega. Veeb pakub neile uusi võimalusi oma kogemuste jagamiseks ning toetab ja mõnikord ka asendab off-line-kogukonnas puuduvaid võimalusi. Sellised rühmad rajanevad informatsioonil ja narratiividel ning neil on oluline osa emotsionaalse tasakaalu saavutamisel.

Kay Richardson on osutanud, et riskide ja haiguste arutelu veebikeskkonnas ei pruugi olla objektiivne, kuid see toob esile usalduse ja eksperthinnan- 
gute problemaatika ning õpetab ratsionaalselt kahtlema poliitika, teaduse ja tootjate pealesurutavates seisukohtades (Richardson 2005: 209). Tema hinnangul õpetab veebikeskkond kiiresti mõistma,

- et ühe ala spetsialist ei ole pädev ekspert teisel alal (mikrobioloog ei päde astrofüüsikas);

- et eksterthinnangud erinevad vormi poolest - teaduslik ekspertiis erineb rakenduslikult mingis tööstusharus töötava eksperdi omast;

- et mittespetsialist võib olla mõnikord ja erilise huvi korral konkreetse nähtuse vastu koolitanud end pädevaks eksperdiks;

- et teaduskeel erineb rahvaetümoloogiate ja -filosoofia keelest, kujutistest ja retoorilistest väljendusvahenditest (Richardson 2005: 51).

Artikkel on redigeeritud ja täiendatud versioon Renata Sõukandi e-kursuse "Meditsiin kui kultuurinähtus"(FLSE.00.215, Tartu 2008) jaoks kirjutatud peatükist. Kirjutis on seotud Eesti Teadusfondi grandiga nr 6824.

\section{Kirjandus}

Arst.ee (http://www.arst.ee - 4. juuli 2008).

BNS 2008. Ida-Tallinna keskhaigla tutvustab iPatsiendi portaali (http://www.delfi.ee/ news/eesti/eesti_uudised/article.php?id=18693065 - 4. juuli 2008).

Campbell, Heidi 2005. Exploring Religious Community Online: We are One in the Network. New York: Peter Lang Publishing.

Cowan, Dougas E. 2005. Cyberhenge: Modern Pagans on the Internet. New York: Routledge.

Dawson, Lorne L. \& Cowan, Douglas E. (toim) 2004. Religion Online: Finding Faith on the Internet. New York: Routledge.

Diskussioon Eesti Diabeediliidu internetifoorumis teemal: Ravitseja Viktor (http:// www.diabetes.ee/foorum-teema.php?lk=10073 - 4. juuli 2008).

Eesti Ämmaemandate Ühing (http://www.ammaemand.org.ee/index.php?id=387 4. juuli 2008).

Farmaatsiaalane informatsioon internetis (http://www.ut.ee/ARFA/interfar.htm 4. juuli 2008).

Inimene.ee: Terviseportaal (http://www.inimene.ee - 4. juuli 2008).

Jenkins, Richard 1996. Social Identity. London: Routledge.

Goodman, David 2004. The criteria for open access. Serials Review 30 (4). [Online]. (http://dlist.sir.arizona.edu/archive/00000798/ - 20. märts 2006). 
Kalvet, Tarmo 2006. eHealth country report for ESTONIA (http://www.euser-eu.org/ ShowCase.asp?CaseTitleID=566\&CaseID=1203 - 4. juuli 2008).

Karau, Steven J., \& Williams, Kipling D. 2001. Understanding Individual Motivation in Groups: The Collective Effort Model. Turner, Marlene E. (toim). Groups at Work: Theory and Research. New York: Erlbaum, lk 113-141.

Kavanaugh, Andrea \& Carroll, John M. \& Rosson, Mary Beth \& Zin, Than Than \& Reese, Debbie Denise 2005. Community networks: Where offline communities meet online. Journal of Computer-Mediated Communication, 10:4, article 3 (http:// jcmc.indiana.edu/vol10/issue4/kavanaugh.html - 20. mai 2008).

Kavanaugh, Andrea \& Reese, Debbie Denise \& Carroll, John M., \& Rosson, Mary Beth 2003. Weak ties in networked communities. Huysman, Marleen \& Wenger, Etienne \& Wulf, Volker (toim). Communities \& Technologies. The Netherlands: Kluwer Academic Publishers.

Kleinman, Arthur 1980. Patients and healers in the context of culture: An exploration of the boderland between anthropology, medicine and psychiatry. Comparative studies of health systems and medical care 3. Berkeley: University of Californian Press.

Kliinik.ee (http://www.kliinik.ee - 4. juuli 2008).

Kollock, Peter \& Smith, Marc (toim) 1999. Communities in Cyberspace. London: Routledge.

Kõiva, Mare 1995. Loitsust riituseni. Hiiemäe, Mall \& Kõiva, Mare (toim). Rahvausund tänapäeval. Tartu: EKI, lk 356-378.

Kõiva, Mare 2008. On-line-intervjuu Vormsi Ennuga. Käsikiri.

Lengel, Laura \& Tomic, Alice \& Thurlow, Crispin 2004. Computer Mediated Communication. London: Sage.

Perearstikeskus.ee (http://www.perearstikeskus.ee - 4. juuli 2008).

Putnam, Robert D. 2000. Bowling Alone: The collapse and Revival of American Community. New York: Simon \& Schuster.

Ravimiamet (http://www.ravimiamet.ee - 4. juuli 2008).

Raviminfo.ee (http://www.raviminfo.ee - 4. juuli 2008).

Richardson, Kay 2005. Internet Discourse And Health Debates. London: Palgrave \& MacMillan.

Rodgers, Shelly, \& Chen, Qimei 2005. Internet Community Group Participation: Psychosocial Benefits for Women with Breast Cancer. Journal of Computer-Mediated Communication, 10 (4), article 5 (http://jcmc.indiana.edu/vol10/issue4/rodgers.html - 30. juuni 2008)

Ryan, Marie-Laure (toim) 2004. Narrative Across Media: The Languages of Storytelling. Lincoln: University of Nebraska Press.

Ryan, Marie-Laure 1991. Possible Worlds, Artificial Intelligence, and Narrative Theory. Bloomington: Indiana University Press. 
Shklovski, Irina \& Kraut, Robert E. \& Rainie, Lee 2004. Shklovski, Irina \& Kraut, Robert E \& Rainie, Lee. The Internet and Social Relationships: Contrasting CrossSectional and Longitudinal Analyses. Journal of Computer-Mediated Communication, 10(1). (http://jcmc.indiana.edu/vol10/issue1/shklovski_kraut.html - 4. juuli 2008)

Sein, Kati 1998. Arvutivõrk Eestis aastatel 1990-1993. Seminaritöö. Tartu: Tartu Ülikooli filosoofiateaduskonna ajaloo osakond.

Singer, Merill \& Baer, Hans 1995. Critical Medical Anthropology. Critical Approaches in the Health Social Sciences; Political Economy of Health Care. Amitwill, New York: Baywood Publishing Company.

Tartu Ülikooli Kliinikum (http://www.kliinikum.ee - 4. juuli 2008).

Wienker-Piepho, Sabine 2000. Mobiiltelefonijutud ehk mobiiltelefonipärimus. Kõiva, Mare (toim). Meedia. Folkloor. Mütoloogia. Tänapäeva folkloorist III. Tartu: Eesti Kirjandusmuuseumi rahvausundi töörühm, lk 9-31. (http://www.folklore.ee/pubte/meedia/ - 4. juuli 2008).

\title{
Summary
}

\section{Medicine on-line}

\author{
Mare Kõiva
}

Key words: communication, computer-mediated communication, disease narrative, doctor-patient communication, online medicine, patient narrative

The adaptation of information technology to everyday clinical practices coincided with the emergence of online databases, personal medical history and institutional information websites. One of the central issues in online medicine is source credibility. This paper overviews the types and communication of online medical information that have changed the logistics of doctor-patient communication. Inter-doctor communication also benefits from the possibilities for professional communication, and application of multiprofessional knowledge; it helps shape and unify professional terms and nomenclature, guarantees the confidentiality and security of data, while providing easy management of high-quality data; makes provisions for knowledge management and ambulatory e-services.

The paper overviews the information portal Kliinik.ee (www.kliinik.ee, OÜ Tervisenõuanne) which shares medical information made available by medical professionals for non-medics, mostly for patients. The portal offers a range of e-medicine services, such as responses by specialists, psychologists, pharmacists. The Communication groups offer the patients free medical advice, feedback, a second opinion to their treatment scheme, as well as an opportunity to share knowledge and their personal experiences, and receive emotional support.

Writing therapy is becoming increasingly popular and has spontaneously moved online. Today, there are discussion forums available for people suffering from diabetes, cancer and other serious (or incurable) medical problems. The Internet is in many 
respects advantageous for this type of therapy: it provides an opportunity to establish a dialogue with others with a similar condition while protecting one's privacy and anonymity. Medical professionals post comments under their own names which gives them credibility.

Seeking medical help at an institutional site from practising doctors makes the language use and attitudes of the online forum official, polite and serious. A closer look at the construction and vocabulary of the doctor-patient communication act reveals that the most common features are formality and distancing - the partners are not equal in their sociopolitical standing. Inter-patient discussion groups are more varied in their style of communication and language use, ranging from informational notices to narratives and displays of emotion. A discussion concerning a visit to a folk healer is treated at more length. Interaction of this kind is a discussion that preserves the individual characteristics of many people in writing. Opinions are individualised, making the discussion similar to oral dialogue in which different strategies are used in reasoning. The posted messages reflect natural personal language use in forms ranging from informational notices to lengthy narratives. The general attitude is supportive and trusting towards official medicine and the personal reactions to social and situational events.

A medical discussion board comprises a conditional group that does not form a network or community but engages in a dialogue to obtain and provide expert opinion. Users of patients' discussion group and their narratives have a close connection to reality. The Internet offers the users new ways to share their practices and experiences and sometimes supports or even provides alternatives not available in offline reality. Such groups are based on information sharing and narratives and play an important role in maintaining emotional stability. 